\title{
The Importance of Fitting Personality Dimensions and Job Characteristics in Employees in the Hotel Management
}

\author{
Ana Jovičić, Tamara Milanović, Milorad Todorović, Dunja Vujičić* \\ Received: March 2011 | Accepted: July 2011
}

\begin{abstract}
The aim of this paper is to present the importance of the connection between personality dimensions of employees with the characteristics of their job in order to achieve more productive work and accomplish maximum customer satisfaction, as well as to create competitive advantage. The survey was conducted on a sample of 50 employees in the hotel "Prezident" in Novi Sad. In the survey was used the questionnaire of personality dimensions of the big five, and traits that have been described in this questionnaire are extroversion, conscientiousness, pleasantness, openness to new experiences and negative affectivity. The results of the survey show that in the selected facility prevail positive personality dimensions, and the negative affectivity is at its lowest level. For that reason this hotel should serve as an example of how to coordinate work in hotel management with the personality dimensions of employees, all in the service of satisfaction of guests. In that sense a very important role has the sector of human resources whose task is identifying personality characteristics and fitting personality characteristics with business activities that an individual performs, and the development of emotional intelligence which is especially important in hotel management.
\end{abstract}

Key words: personality dimensions, Big Five Model, emotional intelligence in hotel management

\section{Introduction}

The behaviour of the individual is determined by the characteristics of his/her personality. To be able to understand and predict satisfaction with job in hotel management, it is necessary to determine which personality characteristics are necessary to achieve the required quality of service. The most important classification of features, characteristic or trait of personality resulted in five big personality dimensions and the paper gives special attention to this subject. Fitting of the personal characteristics with requirements is important in order to achieve satisfaction of employees who are essential for achieving satisfaction of guests. The

\footnotetext{
* University of Novi Sad, Faculty of Sciences, Department of Geography, Tourism and Hotel Management, Trg Dositeja Obradovića 3, Novi Sad, e-mail: ana.jovicic@fondmt.rs
} 
theme of this work is the importance of fitting personality dimensions and job characteristics in employees in hotel management for the satisfaction of service users. The aim is to present the importance of the connection of personality dimensions of the employees with characteristics of their job in order to achieve more productive work and accomplish maximum satisfaction of service users as well as creating competitive advantage.

Ho: Fitting of personality dimensions and job characteristics in employees in hotel management sector affects their job satisfaction and the quality of service provided to guests, and thus affects the satisfaction of guests.

The methods that will be used in the paper are: office research, survey research and deduction method.

On the basis of relevant bibliography, the expected result of the office research is to show the importance of the connection between personality dimensions and job characteristics in a specific hotel management sector where there is a high level of emotional exchange between employees-customers and how that connection of personality dimensions and job characteristics affects the employee's job satisfaction and guest satisfaction.

\section{The personality of employees and their importance in the hotel management sector}

Employees with their knowledge and skills form the backbone of successful business. In the hotel management people create, offer and provide services, and the quality of service is associated with the quality of work relating to the special knowledge and skills in hotel management, general culture and etiquette, as well as technological knowledge and processes, through which the specificity of personnel in hotel management is reflected (Cerovic, 1994).

Employees at all levels are an essential part of an organization and their full involvement enables the use of their abilities to achieve well-being of the organization. All hotel organizations should be lead by the fact that it is not possible to develop a high level of guest satisfaction if the employees in the organization are not satisfied (Bordas, 2005).

To highlight speciality of personnel in hotel management, it is necessary to bring them into correlation with the guests. In the personal contact with a guest it is necessary to recognize his/her wishes and needs and to incorporate them into a quality service that becomes specific and to some extent personalized, contributing to customer satisfaction (Tomasevic, Krizanac, 2009).

In order to be able to assess what sort of staff are needed in hotel management it is necessary to be dedicated to the analysis of the personality of each employee. The personality of employees is a major factor of individual behaviour in hotel management. Differences in personalities lead to different behaviour of individuals, and it leads to a variety of productivity and job satisfaction. It is therefore very important to match employee traits as much as it is possible with the kind of job he/she needs perform.

According to Carver and Sierra personality is a dynamic organization of psycho-physical system within the person that creates the characteristic behaviour, thinking and feeling of that person (Nedeljkovic, Hadzic, 2009).

Two basic factors of personality are the heritage and environment in which a person matures and works. Some authors add also situation to that as a corrective factor. Heritage refers to the physical predispositions and genetic endowment. The environment includes factors such as family, social group, social class, profession, national culture and more. The influence of national culture on the personality of employees is not crucial. However, differ- 
ent national cultures will lead to the fact, that certain types of personality employed in certain cultures, occur more frequently than in the others. This is due to favouring certain characteristics or personality traits in a given culture. Depending on which features are more valued in that society, there will be a greater development of those features. From the point of hotel management it can be noted that for example Greeks and Spaniards are excellent and hospitable hotel and restaurant staff, the French avoid talking in English with tourists.

A significant contribution to this issue was given by Hofstede and McCrae in 2004, suggesting that the culture of a particular social group is partly formed as an aggregate dimension of personalities of members in the group and that the value systems and their associated institutions can be seen from the perspective of social adaptation on the psychological environment that reflects the distribution of personality features of members in a social group (Nedeljkovic, et al., 2OIO).

The situation as a factor may rarely create a certain personality feature if a person does not have it, but it can emphasize a hidden feature the person did not even know he/she has had it.

\section{Abilities of employees}

Big difference among the personalities of employees can be observed by looking at development of their abilities. Abilities can be divided into intellectual and physical. The intellectual skills include: verbal ability, the ability of orientation in space, deduction, memory, numerical ability, reasoning ability and perception (Robbins, 2003). Employees who want to deal with finances should have developed numerical and didactical skills, while employed in the sector for market research should have a capacity of reasoning and memory.

Physical abilities include motor and physical skills. Motor skills are the ability to physically manipulate things in the surrounding (Petkovic et al, 2005). For jobs in the hotel management are very important motor skills because the speed is necessary while providing services, and physical form is required for certain physical activities and as incentive to sustain the effort that work in hotel management requires.

\section{Biographical characteristics of employees}

Biographical characteristics, such as age, sex, marital status and length of service, have also the impact on the personality and behaviour of employees (Petkovic et al, 2005).

With age comes a decline in physical and partly intellectual abilities, leading to loss in productivity, but on the other hand, there is experience which delivers increased productivity. In the sector of hotel management jobs that are in direct contact with guests are usually done by younger people because in hotel management fast movements and their coordination are required, strength to withstand the strain and quickly adapt to new working conditions.

Gender does not affect productivity at work. According to some researches, women are more desirable in certain posts in the hotel management because they proved to be more productive and responsible, and their customers have more confidence in them. These are, for example, receptionist jobs, hotel managers, cooks, maids, etc...

Marital status has little impact on behaviour at work. Employees in the hotel management often sacrifice their social life, which is most evident in employees in managerial positions. 
Work experience affects the productivity. Its influence is reflected in the fact that employees who have spent more time at one post in the same organization are more satisfied, have more routine, and are therefore more efficient and productive.

\section{Maturity dimensions of employees personalities}

Maturity of a person is important feature of personality. Argyris observed dimensions of personality in the context of his/her development. He found that personality of every person develops from immature to mature according to specific dimensions. Levinson noted that this development goes in cycles and not continuously, and he stated a hypothesis that those cycles are: up to I8 years, from I8 to 30 years, from 30 to 45 years and from 45 onwards (Schermerhorn, Hunt, Osborn, 2005). Dimensions of mature and immature personality can be seen from the following table:

Table 1. Dimensions of maturity of personality

\begin{tabular}{|l|l|}
\hline Mature personality & Immature personality \\
\hline Activity & Passivity \\
\hline Independence & Dependence \\
\hline Diverse behaviour & Unilateral behaviour \\
\hline Deeper interest & Superficial interest \\
\hline Long-term prospects & Short-term prospects \\
\hline The superior position & Subordinated position \\
\hline Self-awareness and control & Lack of self-awareness and control \\
\hline
\end{tabular}

Source: Schermerhorn, Hunt, Osborn, 2005

The hotel management requires a mature person because he/she is stable, ready to work and reliable. The person becomes more mature with age and it is important to observe that maturity from the aspect of employment of staff in hotel management. An immature person is not suitable for work in the hotel management because responsibility, serenity, activity and other features necessary for productive work are important in that kind of job.

\section{Dimensions of personality according to theory of the Big Five}

Knowing the personality characteristics of employees is very important, so that we could, to some extent, predict and control the behaviour of employees. Depending on the type of task, we choose the personality types that will suit those jobs. The most important classification of features, characteristics or personality traits resulted in the model of five big dimensions of personalities (Big Five Model). Using the survey of more than I7OOO features or personality traits five basic dimensions according to which all persons differ, were singled out:

- Extroversion

- Negative affectivity

- Pleasantness

- Diligence

- Openness to new experiences. 
We will briefly explain each of the dimensions.

Extroversion indicates the degree to which the person is social and communicative, i.e. satisfied with relations towards the others. Introverted, unsociable, reserved people are less prone to enter the social interaction (Petkovic et al, 2005). Attributes of extroverted people are: liveliness, warmth, sociability, dominance of empathy (Hadzic, Nedeljkovic, 2009).

Negative affectivity is a dimension that has at one side emotional stability, security and tranquillity, while at the other it has nervousness, uncertainty and distrust (Petkovic et al, 2005). Characteristics of people with expressed strong negative affectivity are: lack of emotional stability, the presence of pressure, the presence of dissatisfaction and concern (Hadzic, Nedeljkovic, 2009).

Pleasantness or consent is a dimension of personality which on one side of the extreme has: cooperation, warmth, trust, while on the other side it has: antagonism, coldness, lack of trust (Petkovic et al, 2005). Some of the attributes that a pleasant person has are: consideration and kindness towards the others, lack of dominance over the others, avoidance of conflict, the willingness to forgive the others (Hadzic, Nedeljkovic, 2009).

Conscientiousness is a dimension that has on the one side reliability and confidentiality, and on the other side uncertainty and distrust (Petkovic et al, 2005). Some of the attributes that a conscientious person has are: respect for rules, perfectionism, and systematic approach to planning and executing tasks, rigidity and conformity (Hadzic, Nedeljkovic, 2009).

Openness to new experiences is a dimension of personality that on the one side has the characteristics such as: creativity, originality, curiosity, and openness to new experiences, imagination, unconventionality and a tendency to risk. On the other hand, a person that does not possess this feature is reserved, conventional, conservative, unimaginative, has aversion towards the risk and so on (Petkovic et al, 2005).

\section{Researching of personality dimensions at the Hotel "Prezident" in Novi Sad according to the Big Five Model}

\section{Methodology}

To better examine the dimensions of personality in practice, a survey was conducted in the hotel "Prezident" in Novi Sad. The survey refers to the dimensions of personalities of employees in this hotel and it was conducted on a selected sample of 50 persons employed in this facility. It should be noted that the number of employees varies by seasons. In the sample there were 22 employees of male gender and 28 employees of female gender. Research shows that staff who work in this hotel is predominantly young population. From the age of $2 \mathrm{O}$ to $3 \mathrm{O}$ years there are 28 respondents, from 30 to $4 \mathrm{O}$ years there are $\mathrm{I} 8$ respondents, while from the age of 40 to 50 years there are three, and only one respondent is over 50 years old.

Questionnaire of the personality dimensions of the Big Five has been composed of 25 questions and the staff has been given to indicate to what extent were the statements in the questionnaire according to their self-image. On the scale from I to 5 they were supposed to evaluate the degree of agreement with given statements, relating to dimensions of personality, which mark the ends of the continuum, where the left end of the continuum assesses by grade I, and the right end of the continuum is evaluated with the grade 5 . For each of five personality dimensions five continuum are given. By that I stands for completely false, 
2 for partly false, 3 for correct and incorrect, 4 for partially correct, and 5 stands for absolutely true.

The features that are described in this questionnaire are extroversion, conscientiousness, pleasantness, openness to new experiences and negative affectivity. For each feature a set of five questions that are consistent with the Big Five personality traits have been given.

For extroversion were related the following statements:

- I am usually full of energy;

- It is easy for me to adjust;

- I believe that I am able to be a leader;

- I am full of enthusiasm;

- I am very sociable.

For conscientiousness were related the following statements:

- I have a strong will;

- I have a goal to which I aspire;

- I stand by my ideas and principles;

- I take responsibility for my actions;

- I behave prudently.

For pleasantness were related the following statements:

- I like working with people;

- I like to do small joys to the loved ones;

- The family is important in my life;

- People accept me easily;

- I gladly praise the others.

For openness to new experiences were related the following statements:

- I am imaginative;

- I think a lot about different things;

- I prefer routine tasks;

- I am an original person;

- I am creative.

For negative affectivity were related the following statements:

- I am often moody;

- I care a lot;

- I often feel lonely;

- I am often tense;

- Sometimes I feel empty.

\section{Research results}

The obtained results have been shown graphically; where for each of the five dimensions of personality the distribution of values on a scale from I to 5 can be seen. The average values of this dimension of personality according to the age and gender of respondents have been presented. 


\section{Bfe}

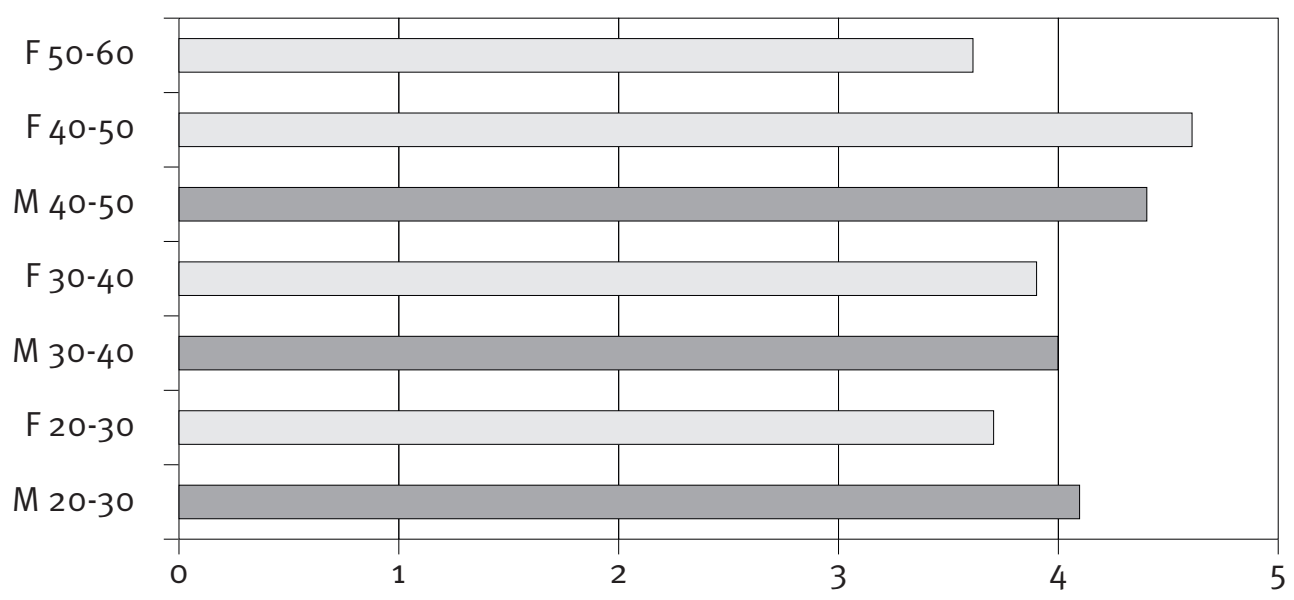

Figure 1 Personality dimension of extraversion

The most important feature of the employees that contributes to satisfaction of guests in the hotel is extroversion. Extroverts are friendly and open people, always ready for communication and social interaction with other people. They are communicative and have good relationships with co-workers.

During the research we came to an interesting fact that the highest degree of extroversion have people who are between 4O-5O years old, both men and women. In this hotel, a high degree of personality dimension of extroversion has most of the staff, which is very positive. To explain better why people in mature age show high level of extroversion, it is important to note that in this age group experience comes to the fore, and they know what guests want.

The next researched feature is the openness to new experiences and independence at work. People who are open easily come to an idea how to meet the guests needs in a spe-

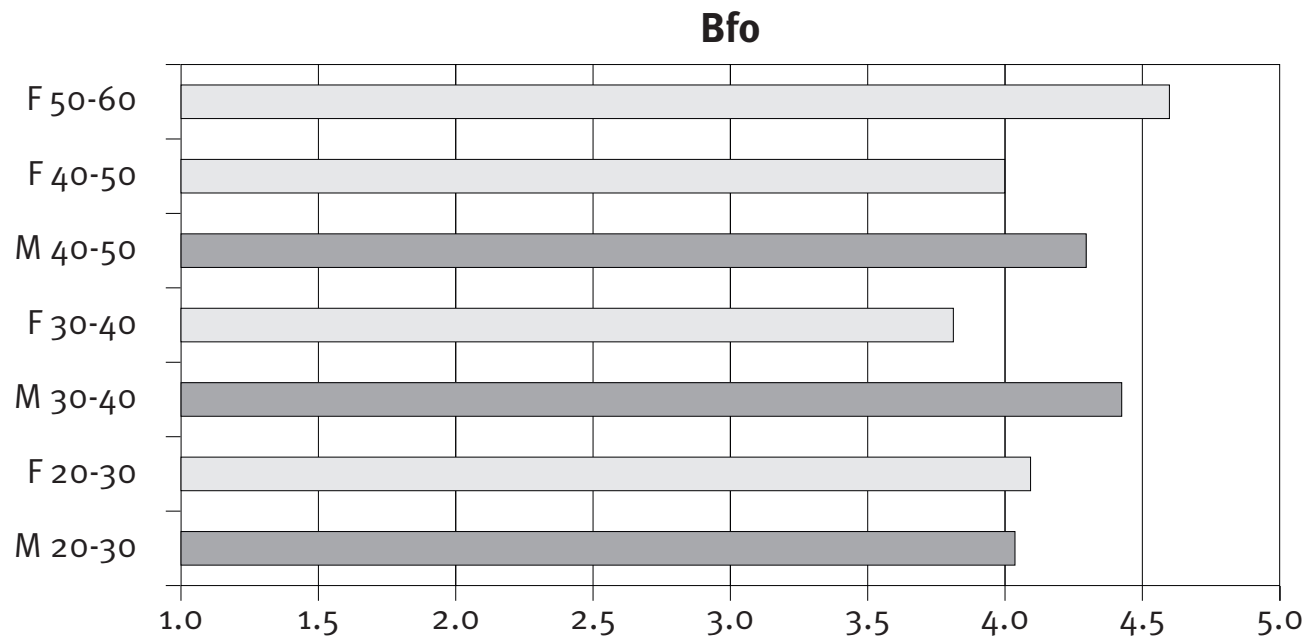

Figure 2 Personality dimension openness to new experiences 


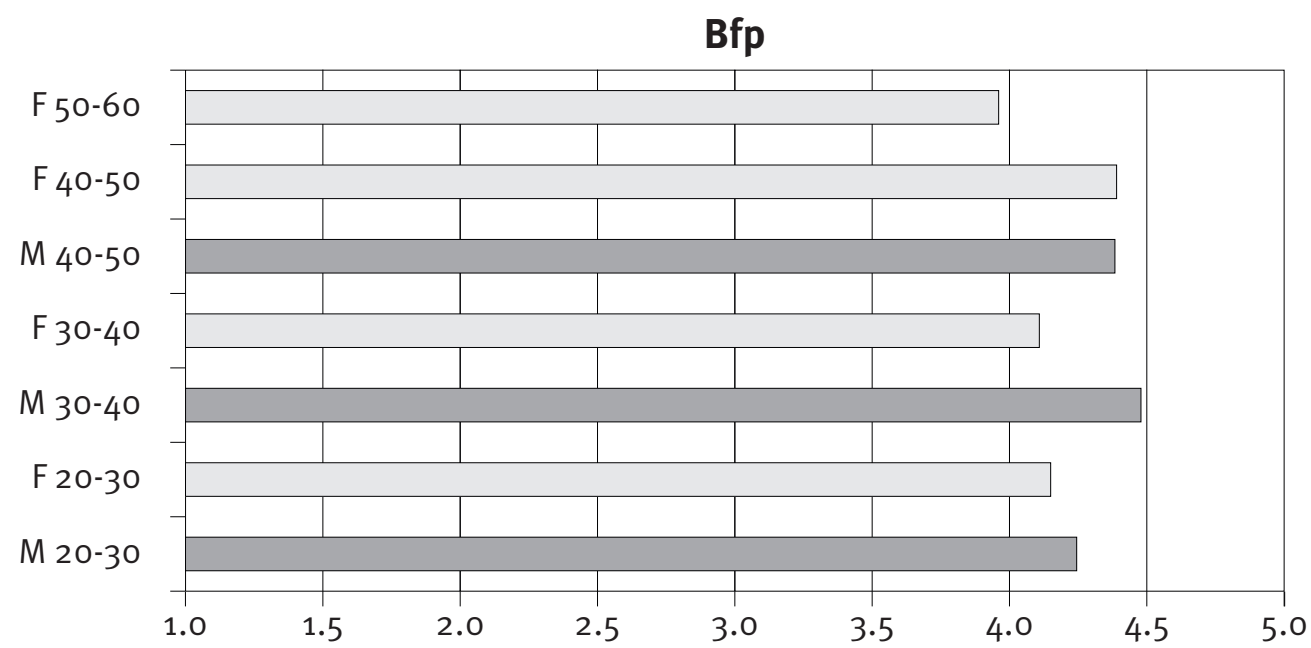

Figure 3 Personality dimension openness to new experiences

cial way and that ability should be constantly encouraged. Openness to new experiences is a dimension of personality that is especially desirable in the hotel management.

Women that are between 50-60 years old have the highest level of openness, but this fact is irrelevant because a small number of people belong to that profile. Interestingly, men, aged from 30 to $4 \mathrm{O}$ and from $4 \mathrm{O}$ to $5 \mathrm{O}$ showed the highest degree of personality dimension openness to new experiences. Although in some other studies men also showed as more open to new experiences, here their age come to a special importance. According to the rule younger people should be more prone to this feature, but here it turned out otherwise. This can be explained by the fact that more mature people are more satisfied with themselves because they have already achieved certain goals. Considering the fact that these people are mainly engaged in hotel management for long period of time, they already know how to creatively meet the wishes of guests which contributes to increasing of openness. Men and women aged between 20 and 30 have proven to be very open to new experiences, which is very positive because they are the future of this facility. As for women aged between 30 and 40 , it is interesting that they showed as the least open to new experiences, while women aged between $4 \mathrm{O}$ and $5 \mathrm{O}$ showed a positive degree of openness to new experiences. This can be explained by the fact that women aged between 30 and 40 years are more reserved because at that time they usually devote themselves to family and they are not willing to risk and the most important to them is comfort and to perform the job as easy as possible, with no extra effort, because at home they invest great energy and creativity, which seems exhausting. Women aged between $4 \mathrm{O}$ and $5 \mathrm{O}$ have passed this period of life and are again ready for new work challenges.

Next examined personality dimension was pleasantness. Pleasant people are trying to foster interpersonal relations. These people are sacrificing and always willing to help others. They usually put the needs of the others before their own. This feature is required in hotel management for these people encourage team work and in relations with guests do their best.

Research has shown that men have a higher level of personality dimension pleasantness than women. Men aged between $4 \mathrm{O}$ and $5 \mathrm{O}$ proved to be the most pleasant. Experience shows that it is sometimes easier and more pleasant to work with men, so this research is not 
so unusual. Men showed a greater degree of pleasantness in this research and we can explain that by the fact that they are not as prone to stress and worries. Women aged between $4 \mathrm{O}$ and 50 have proven to be the most pleasant. Women are more prone to stress, especially in the period of life when they should have accomplished something in all segments, it could be the reason that their level of kindness is not as high as in men. But we should take into account that their score is also very high.

The next examined personality dimension is conscientiousness. People with a high degree of conscientiousness are stubborn, persistent in achieving their goals, responsible and have a high achievement motive. These individuals feel that they have invested much effort into their work and that they need to be adequately repaid. These people are highly desirable in the hotel management business because they are very reliable and great confidence can be given to them.

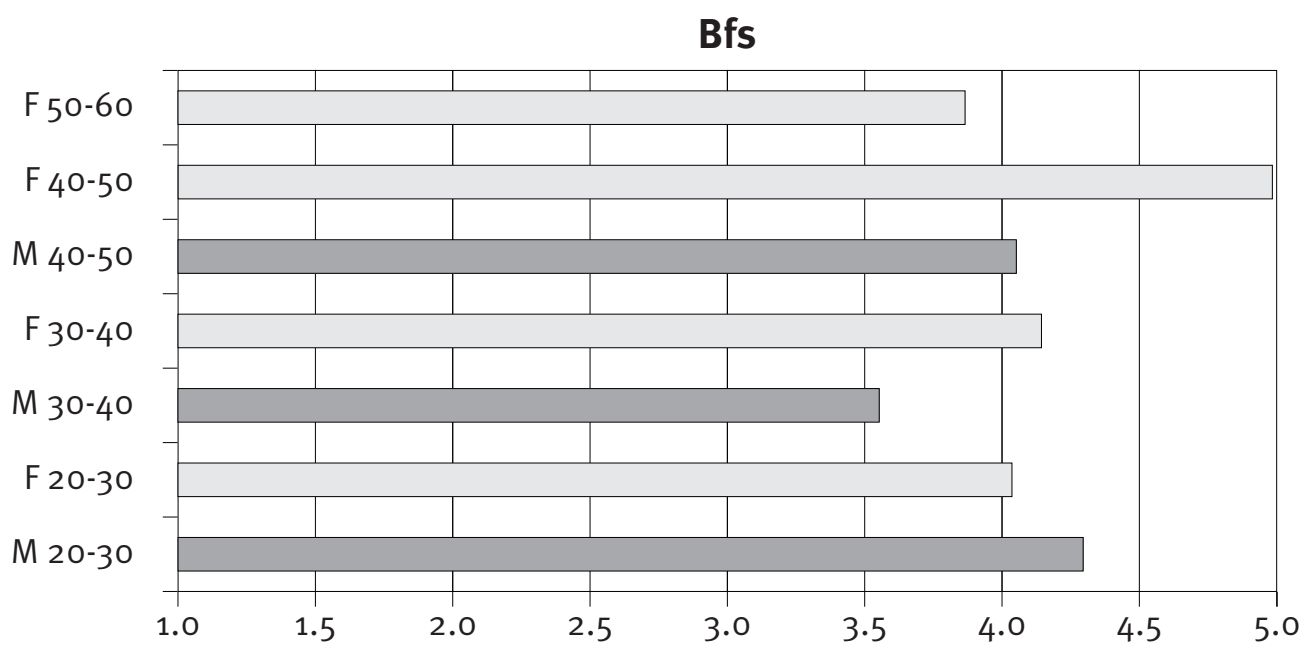

Figure 4 Personality dimension conscientiousness

Researches show that the highest degree of conscientiousness have men, aged from 20 to $3 \mathrm{O}$, and women aged from $3 \mathrm{O}$ to $4 \mathrm{O}$. These results can be explained by the fact that men who belong to this age group tend to prove themselves and they tend to meet the needs of guests, as well as the goals of hotels and they want their work to be rewarded. Women, aged from 30 to 40 want to be secure in their position in the hotel company, and by all means try to win the sympathy of their superiors even though at that age sometimes they have other preferences than business success. Interestingly, men aged between $3 \mathrm{O}$ and $4 \mathrm{O}$ have the lowest rate of conscientiousness. They should then be focused on a career, but it is possible that they were pushed by women in this facility because there are more of them, on the basis of this research we can conclude that they are very effective, at least if it is about a degree of conscientiousness.

The following personality dimension which was researched is negative affectivity. In this hotel, according to surveys, the degree of negative affectivity was very low indicating that in this hotel negative affectivity is on the minimum level. It is very important for this study because people with a high degree of affectivity are not suitable for all types of jobs in the hotel management. In this case there are very few of these persons and that shows to the pos- 


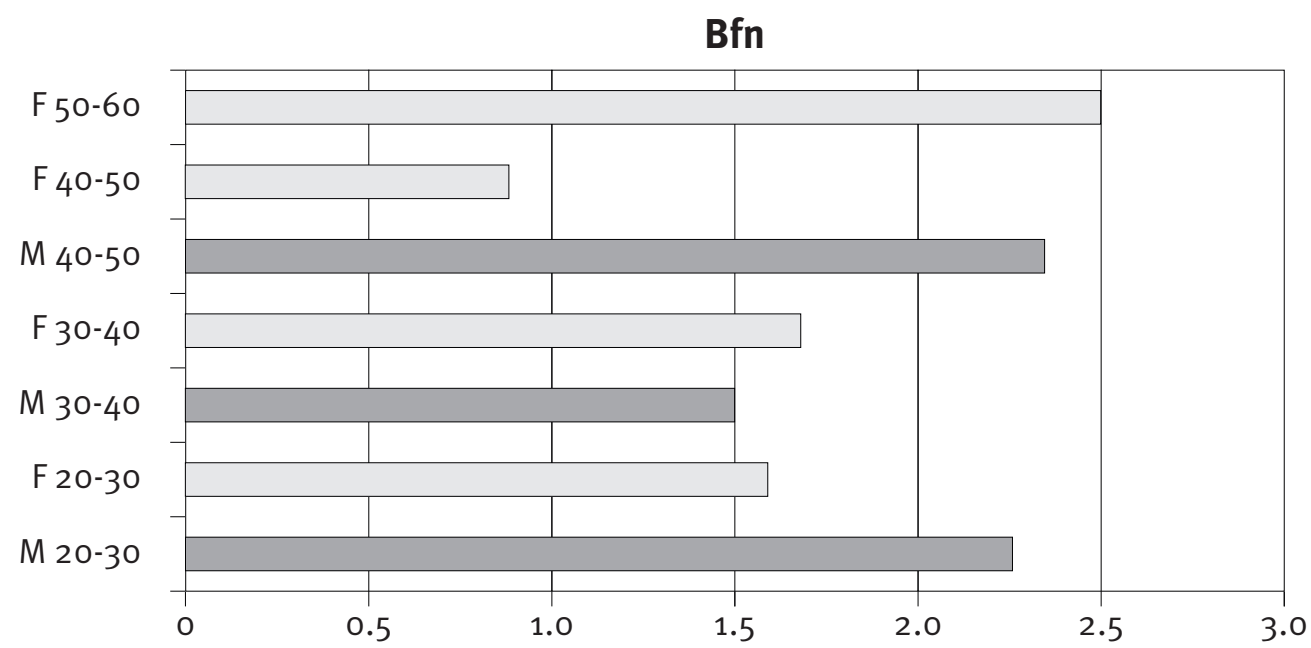

Figure 5 Personality dimension negative affectivity

itive fact that the leaders while hiring staff have observed the features of personnel before they entered this hotel community.

The lowest level of negative affectivity showed women, aged between $4 \mathrm{O}$ and $5 \mathrm{O}$ and from 50 to 60 years, but it is important to note that this is not relevant fact because there were few respondents that belonged to this age group. Attention should be paid to men aged between $2 \mathrm{O}$ and $3 \mathrm{O}$, and also between $4 \mathrm{O}$ and $5 \mathrm{O}$. These groups showed the highest degree of negative affectivity, though it is not at alarming levels, which is positive. The obtained results can be explained by the fact that the first group of people is at the beginning of their career and that those people have yet to see how the job should be performed. At this time the great dissatisfaction may arise because sometimes those people are not secure in themselves and in their goals. The second group shows people in their middle ages, and it is known that it is very possible that men are then in so-called midlife crisis, when they are dissatisfied with their own achievements, so it is not unusual that they feel a higher dose of negative affectivity than the other groups of people. Women have a relatively low level of negative affectivity, but it can be assumed that this level increases with age. For that reason the superiors should try to control this feature as much as possible because it is not desirable that people with strong negative affectivity perform the work in hotel management.

Hotel "Prezident" proved to be a representative hotel which cares about its employees and while hiring the staff, a great effort is invested in selecting suitable people to work at the facility. It would be preferable that other hotels and restaurants also look upon the hotel "Prezident" because it shows the right way of deployment and employment of staff in the hotel management. Here the positive dimensions of personality dominate, and negative affectivity is at its lowest level. That is why this hotel should serve as an example of how to coordinate work in the hotel management with the personality dimensions of employees, all in the service of guest satisfaction. 


\section{Other personality dimensions that affect the behaviour of individuals in the company}

It is necessary to point out the existence of some other personality dimensions that affect the behaviour of employees in the hotel management, namely: locus of control, Machiavellianism, authoritarianism and dogmatism, self-esteem, self-efficacy, self-observation and willingness to take risk. Locus of control is the degree to which one believes that he/she can control his/her own fate (Kosar, Raseta, 2005). People with an internal locus of control believe that everything that happens is the result of their actions. People with external locus of control believe they have no control over their lives and that everything that happens is the result of others or faith. People employed in the hotel management should have the internal locus of control, while people with external locus of control are not adequate to work in the hotel management (Schermerhorn et al, 2005).

Machiavellianism as a personality trait shows to what extent the person behaves in a manner consistent with the principles of Machiavelli: pragmatism, arrogance, power, emotional distance, the end justifies the means. People with high degree of Machiavellianism engage themselves more in political processes, they negotiate more and have more wins, they are better in the jobs where there are negotiations and emotions are not important. This implies that such people in organizations are good in positions where it is necessary to negotiate, for example the hotel manager job. Risk related to people with a high degree of Machiavellianism is that they have no qualms about unethical behaviour in order to satisfy their interests (Robbins, 2003).

Authoritarianism and dogmatism show the degree of rigidity of personal beliefs. Authoritarian people are very difficult to change their beliefs, are very conventional and they highly respect force, power and authority. Dogmatic people have all the features as well as authoritarian, but in even greater degree. Authoritarian personalities as managers are highly prone to authoritarian leadership style, and as subordinates they respect the authority of the head, but demand from him the certainty, clarity and structure (Ivancevich et al, 2005).

Self-esteem is the degree to which one respects and recognizes himself and his own abilities. It is associated with self-efficacy and thus showing the extent to which people consider their own individual abilities. People with less self-efficacy and self-esteem will show a tendency to depend on other people and they will be less satisfied with work (Luthans, 2005).

Introspection is the degree to which the individual is aware of his/her qualities and ability to adjust his/her qualities and behaviour to the situation. People who have a higher degree of self-introspection are more conscious of themselves and their environment and pay more attention to the behaviour of others in the organization. Since they are aware of what is happening around them and they have greater ability to adapt their behaviour to the environment, no wonder that these people more progress and are more changing their jobs (Ivancevich et al, 2005).

Risk appetite is the degree to which an individual accepts the risk. Risk appetite can be characterized as a good feature of managers in the hotel management. As noted above, the hotel management is a business that requires quick action and decision making, and this speed carries risk. A person with a higher degree of risk preferences can have more chances to successfully run a hotel or a restaurant because there the decisions are made quickly. Therefore, on the managerial posts there are usually people with experience who can deal with this kind of problems. 


\section{The importance of emotional intelligence for employees in the hotel management}

From the point of view of tourist activities, emotional intelligence is an important dimension of personality, which enables people to comprehend the feelings of those around them. In the hotel management the most important relation is employee-guest, when it is necessary that an employee has a highly developed emotional intelligence.

Emotional intelligence consists of two basic types of skills: self management skills and skills of successful cooperation with others. Skills of successful cooperation with others are a priority in business in the hotel management, but the person first of all must control himself/ herself in order to be able to enter into successful interactions with other people.

When it comes to management skills then we have in mind the developed self-awareness, self-control and motivation.

All researches indicate that emotional intelligence can be developed. In contrast to the intellectual functioning that can develop in certain years up to certain limits, emotional intelligence can be developed in all segments, regardless of age. Emotional intelligence can only partly be developed automatically (coming to terms with different situations as they grow). In order to develop properly it is necessary to acquire knowledge and practice new skills constantly until it becomes a habit. It would be desirable that hotels and restaurants pay more attention to emotional intelligence. They should organize training courses to help employees to express their emotions and to solve their problems in a better way. This should also help to familiarize superiors and their employees better in order to know how to approach them to achieve more productive teamwork.

Employers are now looking for emotionally and socially competent workers and they pay them well. Harvard Business School emphasizes the development of empathy and cooperation. Prestigious business schools know that expertise alone is not sufficient, and that if they want to remain a prestigious, the emphasis must be placed precisely on the development of emotional intelligence.

\section{Conclusion}

Hotel management is a work-intensive activity and the work of employees is a critical factor in business success of a certain hotel or restaurant. Staff invests their knowledge, skills and talent in the preparation and provision of catering services. The work of employees is the most important factor in the quality of services which means that the staff provides identity or recognition to a facility.

Within understanding the fitting of personality dimensions with the characteristics of their job, personalities of the hotel or restaurant facility should also be regarded. Every human being has a unique personality, determined by the specific combination of different personality features. Different personality features lead to their very different behaviour in organizations. The personality features of employees in an organization determine its overall activity and profile.

Knowing the personality characteristics of employees is very important so that we could be able to predict and control the behaviour of employees. Depending on the type of the task, we choose the personality types that will suit those jobs.

The Big Five Model examines the following characteristics or personality traits: extroversion, conscientiousness, pleasantness, openness to new experiences and negative affectivity. 
In research carried out at the hotel "Prezident" we came to the conclusion that in the organization prevail positive personality characteristics of employees, while negative affectivity is low, which is extremely important for achieving employee satisfaction, which results in guest satisfaction, as a primary goal of every hotel property.

In that sense, an important role has the sector of human resources which adequately conducts the selection process of employees and job distribution.

Fitting of personality traits with job requirements is very important. This is because the employees with a high degree of fitting between personality dimensions and job characteristics will at the same time be more productive, because they will be able to use their abilities to the maximum, and therefore job satisfaction in the hotel or restaurant will be larger.

This research was conducted on a specific and relatively small sample, and for that reason it would be interesting to conduct similar research on a representative sample. Alignment of business activities with personality dimensions of employees in the hotel management in Serbia would result in increased satisfaction of employees and their higher motivation which would contribute to creating a positive image of hotel management of Serbia in domestic and international market.

\section{References}

Bordas, E. (2005). The latest trends in hotel marketing, HUH INFO - professional news bulletin of the Croatian Association of Hoteliers and Restaurateurs, congress material of 9. Congress of Croatian hoteliers and restaurateurs, Sheraton Hotel Zagreb, Opatija-Zagreb, December 2005, p.5.

Hofstede, G. (2OOI). Culture's consequences: Comparing values, behaviours, institutions and organizations across nations. Thousand Oaks, CA-London, etc. Sage Publications

Hofstede, G., Mccrae, R.R. (2004). Personality and culture revisited, linking traits and dimensions of culture. Cross-Cultural Research, vol. 38, No 52-88

Ivancevich, J., Konopaske, R., Matteson, M. (2005). Organizational Behaviour and Management, McGraw Hill Irwin, Boston

Luthans, F. (2005). Organizational Behaviour, McGraw Hill, Boston

Robbins, S. (2OO3). Organizational Behaviour, Prentice Hall Inc., Englewood Cliffs, New York

Schermerhorn, J., Hunt, J., Osborn, R. (2005), Organizational Behaviour, John Wiley\&Sons, New York

Hadzic, O., Nedeljkovic, M., (2009). Motivation for work and job satisfaction in the organization, Faculty of Science, Department of Geography, Tourism and Hotel Management, Novi Sad

Kosar, Lj., Raseta, S. (2005). Challenges to quality-quality management in hotel management, Advanced School of Hotel Management, Belgrade

Nedeljkovic, S. Kokovic, D. Nedeljkovic, M. (2OIO). The influence of national culture on the behavior of consumers and employees in the tourism sector-application of the theory Hofsted, Collection of Matica srpska of social science, n I3O, p, 43-59

Petkovic, M., Janicijevic, N., Bogicevic, B. (2005). Organization: design, conduct, human resources and changes, Faculty of Economics, Belgrade

Tomasevic, A., Krizanac, M.R., Bujas, N.K, Serdar, D. (2009). Taking care of guests. Agency for Vocational Education, British Council, Zagreb

Cerovic, Z. (1994). Business and management success factors of Hotel Management, PhD thesis, Faculty of Hotel Management Opatija, Opatija 